\title{
Stability Enhancement of Slope with Self Drilling Anchors
}

\author{
Pratibha Singh, Satyendra Mittal \\ Indian Institute of Technology \\ Roorkee, India \\ pratibhasinghcivil@gmail.com; smittfce@iitr.ac.in
}

\begin{abstract}
An experimental study has been conducted to get the behaviour of Self-Drilling Anchors in sandy slope. Some set of experiments were conducted by inserting single anchor and then the experimental results are validated with FEM software Phase ${ }^{2}$. A parametric study has also been conducted on a real slope in Guwahati, India with Phase ${ }^{2}$ software for getting optimised angle of inclination of anchors, length of embedment and Surcharge etc. and the effect of these parameters were noticed on factor of safety of the slope. The slope has also been analysed under pseudo static conditions to check the efficiency of the anchors for hilly slopes situated in earthquake prone areas.
\end{abstract}

Keywords: Slope Stabilisation, Self-drilling anchors, Reinforced slopes, FEM.

\section{Introduction}

Soil anchoring is a method of reinforcing the soil with steel bars which is somewhat similar to soil nailing technology [4] The purpose of inserting anchors/nails is to increase the tensile and shear strength of the soil and restrain its displacements. The self-drilling anchors are used for reinforcing the soil and these are directly driven into the soil and thereafter slurry is injected within the anchor body, to make it like a grouted anchor.

The methodology of design for slope stabilization with steel bars had been developed since the 1980s ([2]; [5]; [1]; [6],[3]). [2] performed a theoretical study to determine the optimum orientation of anchors for stabilization of slopes by employing the concept of surface loads. [1] provided a description of a procedure to evaluate the design of anchored flexible retaining structures, in which the coefficients of variation (c.o.v.) of pullout resistance of anchors in both cohesionless and cohesive soil were proposed. Previous studies on soil anchor have explored both theoretical methods of design [3] and experimental testing thereof in lab. These tests have explored various parameters and their effects on the different properties of soil anchors.

In the present research work, an experimental study has been conducted on slope model of $50^{\circ}$ slope angle and $50 \mathrm{~cm}$ height, prepared in the laboratory in a steel tank of size $100 \mathrm{~cm} \times 60 \mathrm{~cm} \times 80 \mathrm{~cm}$. An anchor was inserted at the centre of the slope face with embedded length as 0.8 times height of the slope. The behaviour of the slope is found in terms of settlement when the surcharge load is applied on the crest of the slope. The slope model has been validated in FEM software Phase ${ }^{2}$ which shows that the experimental results are in good agreement with the FEM results. A parametric study has been conducted on a real slope present in Guwahati, India, to assess the performance of Self drilling anchors for stabilisation of the slope. The results shows that the stability of the slope depends on various properties of the anchors, therefore it is necessary to take care of those parameters while stabilising any slope with the help of anchors.

\section{Experimental Study}

Preparation of slope: The slope $(50 \mathrm{~cm}$ high) has been prepared in layers of $10 \mathrm{~cm}$ thickness, the sand is filled with rainfall technique in which the sand was allowed to freely fall from a height of $1 \mathrm{~m}$ through horizontal screens. Yellow colour dye is used between layers to visualise the displacement of the slope through the perspex sheet at one side of the tank and the moisture content of $6 \%$ is kept to ease the making of the slope. An iron sheet of $45 \mathrm{~cm} \times 45 \mathrm{~cm} \times 1.5 \mathrm{~cm}$ was placed in the middle of the crest to ensure the uniform surcharge loading on the slope. Figures 1 (a) and (b) below shows the sketch of the slope model.

After preparation of the slope, an anchor rod of $32 \mathrm{~mm}$ diameter with cutting bit of $50 \mathrm{~mm}$ dia shown in fig. 1 (c) is installed in the mid height of the slope by facing the cutting bit towards the slope face and then the anchor rod is inserted 
like screws in the wall till the required depth $(0.8 \mathrm{H})$ has been achieved. Then for grouting, the hole in the anchor rod is filled with cement slurry at an ambient pressure with the help of manually operated grouting machine. Then the slope is left for 7 days for setting of the cement slurry inside the anchor and the soil body, so that the bonding between soil and the anchor and soil particles improves.
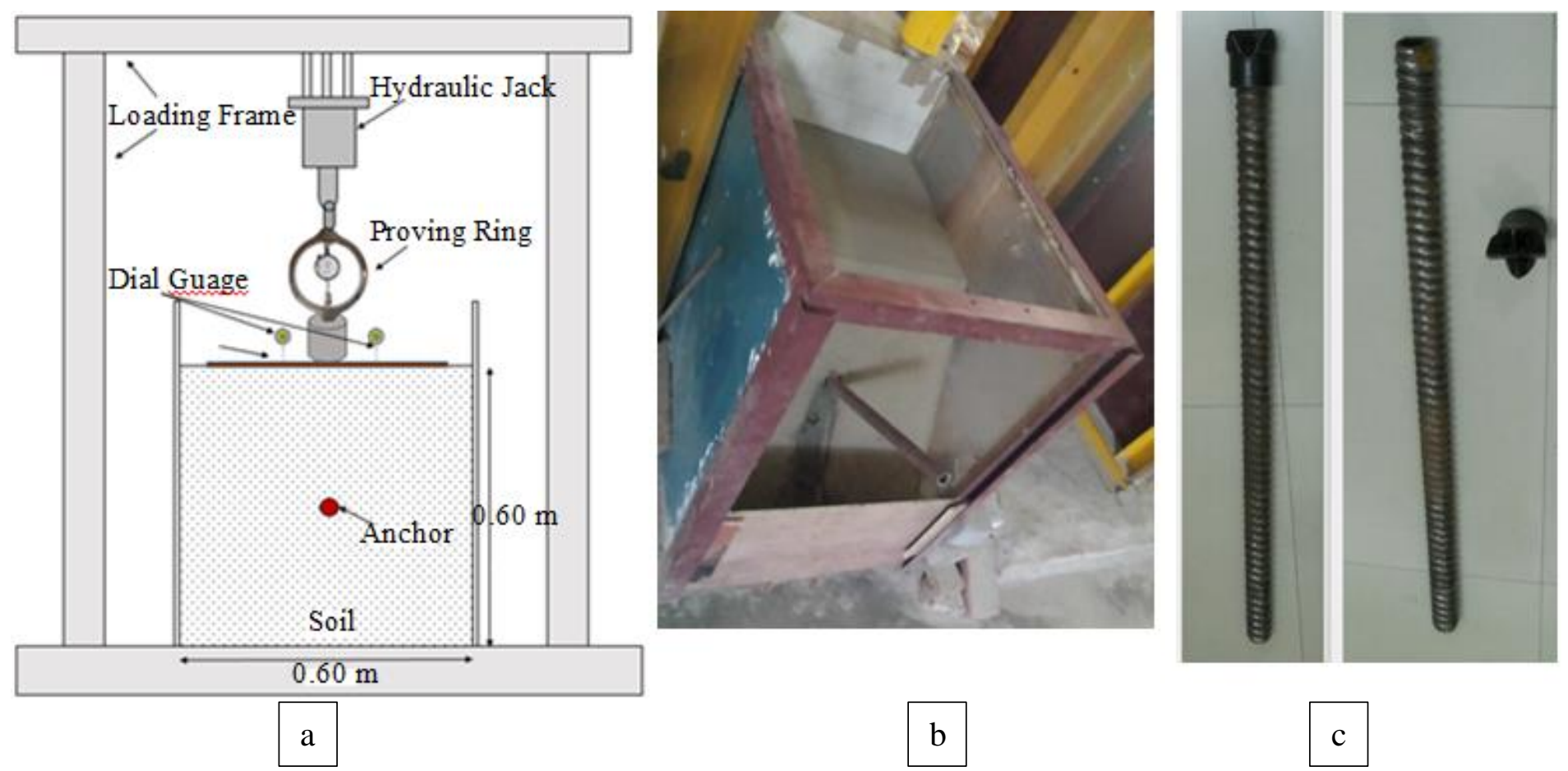

Fig. 1: a) Sketch of experimental setup b) Experimental setup c) Self Drilling Anchor rod and cutting bit.

Testing of the slope model: The model setup is tested for two cases i.e. in the presence and absence of cement slurry with angle of inclination of anchor (i) as 100. Surcharge load is given to the iron plate at the crest of the slope with the help of hydraulic jack and proving ring setup and the settlement corresponding to each load increment (at an interval of 0.25 $\mathrm{kN}$ ) is noted down in 4 dial gauges kept at 4 corners of the plate. Table 1 below show properties of soil and anchors for the experimental testing.

Table :. Properties of Soil and Self-drilling Anchors for Experimental Work.

\begin{tabular}{|c|c|c|c|c|c|c|c|c|c|}
\hline Property & $\begin{array}{l}\text { Slope } \\
\text { Angle }\end{array}$ & $\begin{array}{l}\text { Height of } \\
\text { Slope (m) }\end{array}$ & \begin{tabular}{ll}
\multicolumn{2}{l}{ Cohesion } \\
of & soil \\
$(\mathrm{kPa})$ &
\end{tabular} & $\begin{array}{l}\text { Angle of } \\
\text { friction of } \\
\text { soil }\end{array}$ & $\begin{array}{l}\text { Elasticity } \\
\text { Modulus of } \\
\text { soil } \\
(\mathrm{kPa})\end{array}$ & $\begin{array}{l}\text { Elasticity } \\
\text { Modulus } \\
\text { of } \\
\text { Anchor } \\
(\mathrm{kPa})\end{array}$ & $\begin{array}{l}\text { Diameter } \\
\text { of Anchor } \\
(\mathrm{mm})\end{array}$ & $\begin{array}{l}\text { Length } \\
\text { of } \\
\text { Anchor } \\
\text { (m) }\end{array}$ & $\begin{array}{l}\text { Bulk } \\
\text { density } \\
\text { of the } \\
\text { soil } \\
\left(\mathrm{kN} / \mathrm{m}^{3}\right)\end{array}$ \\
\hline Symbol & $\alpha$ & H & c & $\phi$ & $\overline{\mathbf{E}_{\mathrm{s}}}$ & $\overline{\mathbf{E}_{\mathbf{a}}}$ & d & $\mathbf{L}$ & $\gamma_{b}$ \\
\hline Value & $50^{\circ}$ & 0.5 & 1 & $31^{0}$ & 20000 & 24000000 & $32 \mathrm{~mm}$ & $0.8 \mathrm{H}$ & 15 \\
\hline
\end{tabular}

Figures 2 (a) and (b) show the cracks and the pattern of failure on the slope face for the anchor with cement slurry and without cement slurry respectively, cracks are less for (a) due to bonding between cement slurry and surrounding soil. Fig.3 (a) shows the load settlement curve for slope reinforced with one anchor (with and without slurry) for $i=10^{0}$. Another three set of tests were conducted with self-drilling anchor (with slurry) by varying angle of inclination of anchors as i) $0^{0}$ ii) $10^{\circ}$ and iii) $15^{\circ}$. The respective load and settlement values were noted for each case and are presented in Fig. 3 (b). 


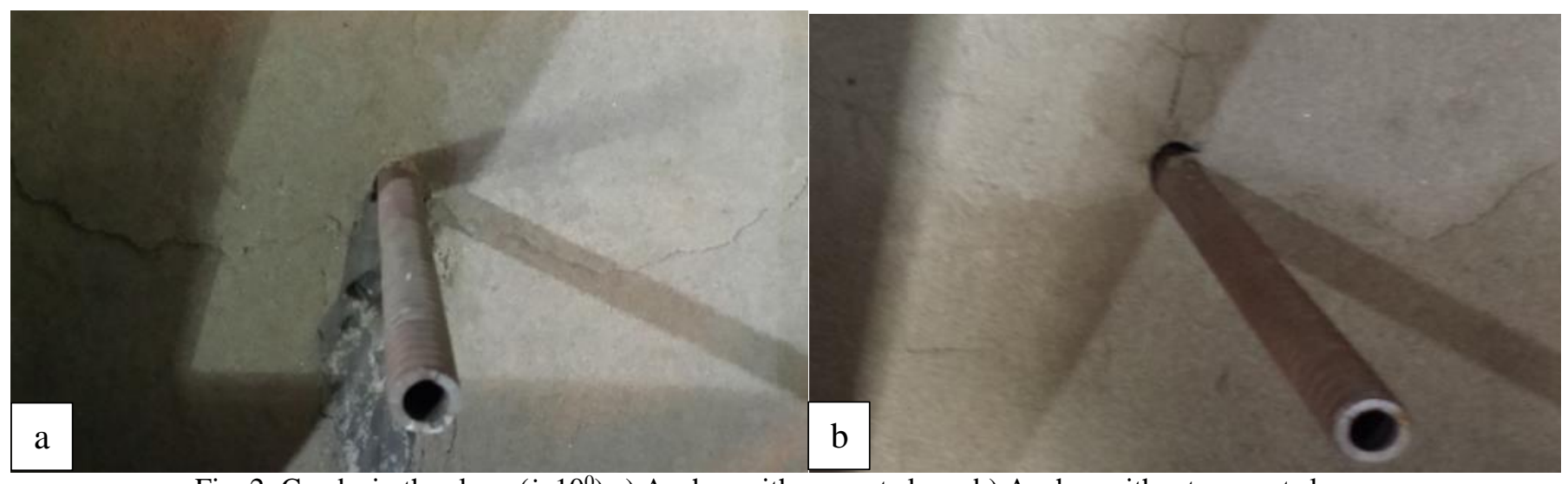

Fig. 2: Cracks in the slope $\left(i=10^{0}\right)$ a) Anchor with cement slurry b) Anchor without cement slurry.

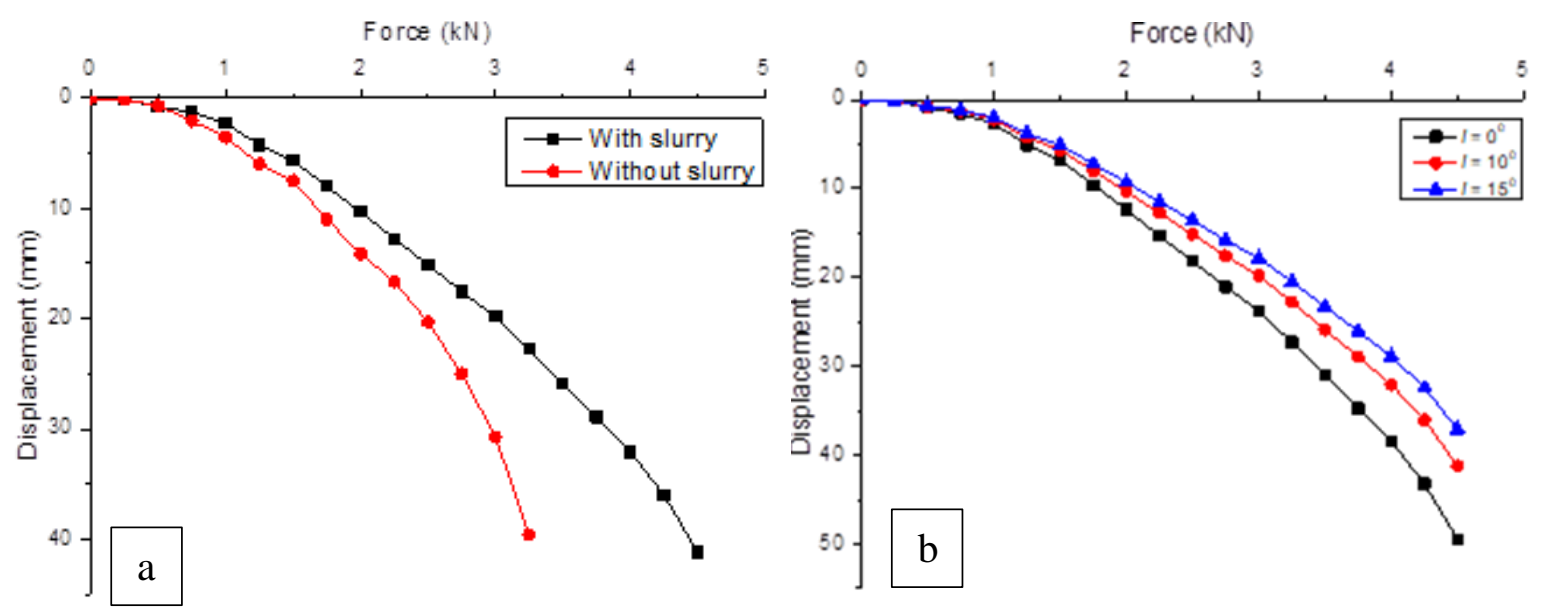

Fig. 3: a) Load settlement curve for anchor with and without slurry for $i=10^{0}$;

b) Load settlement curve for anchor with slurry for $i=5^{0}, 10^{0}$ and $15^{\circ}$.

\section{FEM Modelling of the Slope}

The experimental results are validated by its 2D FEM in Phase ${ }^{2}$ software by taking Mohr-Coulomb's constitutive model for the soil and the anchors were modelled as steel bars by assigning diameter as $32 \mathrm{~mm}$ and Young's modulus of the anchor rod. The properties of the soil and anchors are taken from table 1.

\subsection{Validation of Experimental Results}

The experimental results are validated by its numerical modelling in Phase ${ }^{2}$ in which the soil mass is divided into 6 noded triangular elements. The base of the slope is kept fixed in both $\mathrm{x}-\mathrm{y}$ directions and the sides of the slopes were assigned roller boundary conditions (kept free in y-direction). Fig.4 below shows the boundary conditions, mesh discretisation, loading at the crest, geometry of the slope and position of the anchor.

The stress is applied to the model at the crest in units of $\mathrm{kPa}$. The load applied to the experimental model has also been converted to $\mathrm{kPa}$ by dividing the load by plate area i.e. $0.45 \times 0.45 \mathrm{~m}^{2}$, hence a comparison is done between experimental and FEM results for angle of inclination $i=0^{0}, 10^{\circ}$ and $15^{\circ}$. Fig.5 shows the comparison of the results for experimental setup and FEM model. 


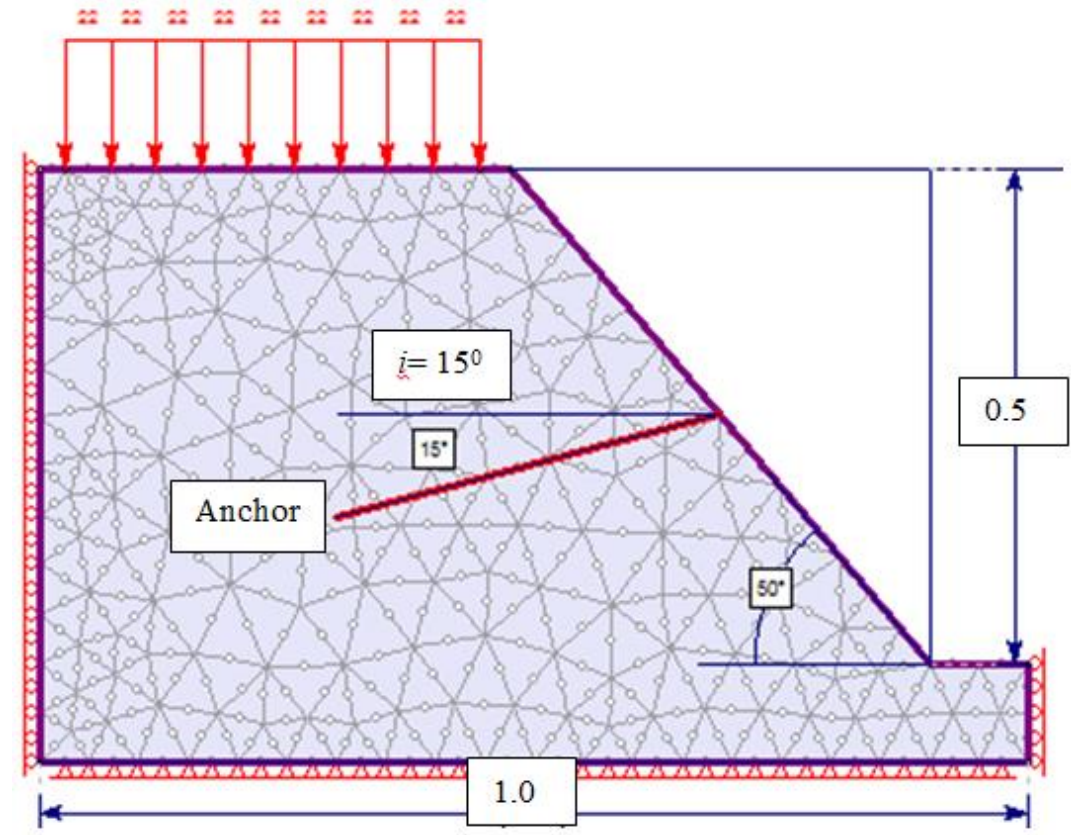

Fig. 4: FEM model of the slope $\left(\alpha=50^{\circ}, i=15^{\circ}\right.$ and $\left.\mathrm{H}=0.5 \mathrm{~m}\right)$, All dimensions are in metres.

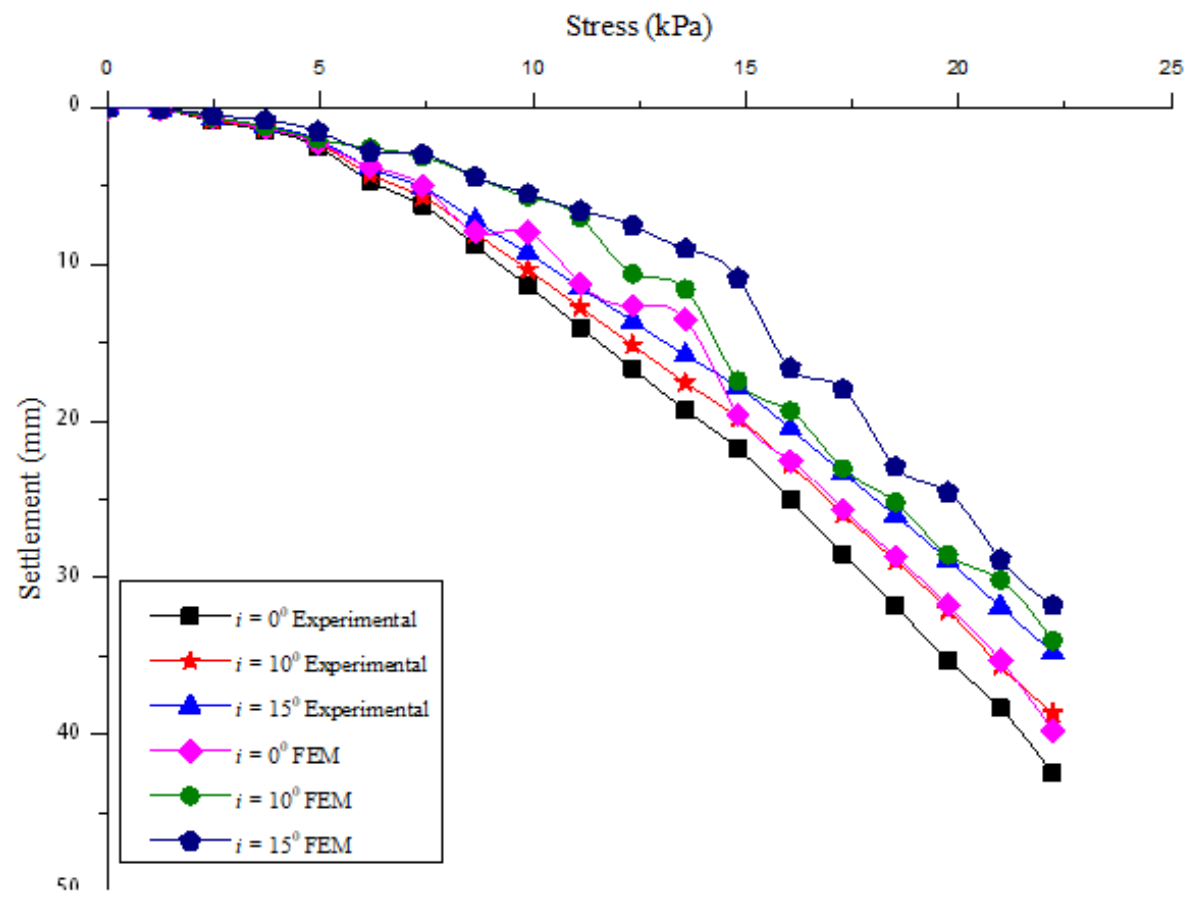

Fig. 5: Validation of Experimental results with FEM model results.

The comparison of the results shows that the displacement values of FEM models are 10 to $30 \%$ less than the experimental values, which may have happened due to the extra weight of the iron plate placed on the crest of the slope for ensuring the uniform distribution of the load coming from the hydraulic jack to the crest of the slope. It is found that Stress-displacement curves from experimental testing and FEM modelling are in accordance with slight variations. 


\subsection{Parametric Study}

As the experimental results were found in agreement with the FEM modelling of the slope reinforced with anchors, therefore keeping the same assumptions and models used for FEM modelling of the slope, a parametric study has been conducted on FEM ( Phase $^{2}$ ) model of a real slope present in Guwahati, India. In this study the factor of safety has been analysed using the shear strength reduction technique which allows to automatically perform a finite element slope stability analysis, and to compute a critical strength reduction factor for the model. Fig. 6 shows the model of the slope analysed without reinforcement of anchors, giving factor of safety as 1.02. Tables 2 and 3 below shows properties which were considered for parametric study.

Table 2: Properties for parametric study.

\begin{tabular}{|l|l|l|l|l|l|}
\hline $\begin{array}{l}\text { Angle of Inclination } \\
\text { of anchors: }(i)\end{array}$ & $\begin{array}{l}\text { Length of embedment of } \\
\text { anchors: }(\mathrm{L})\end{array}$ & $\begin{array}{l}\text { Diameter of } \\
\text { Anchors: }(\mathrm{d})\end{array}$ & $\begin{array}{l}\text { Spacing and Number of } \\
\text { Anchors }\end{array}$ & Surcharge & $\begin{array}{l}\text { Pseudo static } \\
\text { co-efficients }\end{array}$ \\
\hline $\begin{array}{l}0^{0}, 5^{0}, 10^{0}, 15^{0}, 20^{0}, \\
25^{0}\end{array}$ & $0.5 \mathrm{H}, 0.6 \mathrm{H}, 0.7 \mathrm{H}, 0.8 \mathrm{H}$ & $32 \mathrm{~mm}$ & $\begin{array}{l}\mathrm{S}_{\mathrm{v}} \text { and } \mathrm{S}_{\mathrm{h}}=1 \mathrm{~m} \text { to } 2.5 \mathrm{~m}, \\
\text { no of anchors changes } \\
\text { according to spacing }\end{array}$ & $\begin{array}{l}20 \mathrm{kPa} \text { to } \\
100 \mathrm{kPa}\end{array}$ & $\begin{array}{l}\mathrm{a}_{\mathrm{h}}=0.1, \\
0.15, \\
\left.=\mathrm{a}_{\mathrm{h}} / 2\right)\end{array}$ \\
\hline
\end{tabular}

Table 3: Geometry of the slope and the material properties of the soil and anchors.

\begin{tabular}{|c|c|c|c|c|c|c|c|c|c|}
\hline Property & $\begin{array}{l}\text { Avg. } \\
\text { Slope } \\
\text { Angle }\end{array}$ & $\begin{array}{l}\text { Height } \\
\text { of Slope } \\
(\mathrm{m})\end{array}$ & $\begin{array}{l}\text { Cohesion } \\
\text { of soil } \\
(\mathrm{kPa})\end{array}$ & $\begin{array}{l}\text { Angle } \\
\text { of } \\
\text { friction } \\
\text { of soil }\end{array}$ & $\begin{array}{l}\text { Elasticity } \\
\text { Modulus } \\
\text { of soil } \\
(\mathrm{kPa})\end{array}$ & $\begin{array}{l}\text { Elasticity } \\
\text { Modulus } \\
\text { of Anchor } \\
(\mathrm{kPa})\end{array}$ & $\begin{array}{l}\text { Diameter } \\
\text { of } \\
\text { Anchor } \\
(\mathrm{mm})\end{array}$ & $\begin{array}{l}\text { Length } \\
\text { of } \\
\text { Anchors } \\
\text { (m) }\end{array}$ & $\begin{array}{l}\text { Spacing of } \\
\text { Anchors } \\
(\mathrm{m}) \\
\mathrm{S}_{\mathrm{v}}=\text { Vertical } \\
\mathrm{S}_{\mathrm{h}}=\text { Horizontal }\end{array}$ \\
\hline Symbol & $\alpha$ & $\mathbf{H}$ & c & $\varphi$ & $\mathbf{E}_{\mathrm{s}}$ & $\mathbf{E}_{\mathbf{a}}$ & d & $\mathbf{L}$ & $S_{v}$ and $S_{h}$ \\
\hline Value & $50^{0}$ & 19 & 12 & $32^{0}$ & 50000 & 24000000 & $32 \mathrm{~mm}$ & $\begin{array}{l}0.5 \mathrm{H} \text { to } \\
0.8 \mathrm{H}\end{array}$ & 1 to 2.5 \\
\hline
\end{tabular}

Inclination of anchors with horizontal (i): The slope had been analysed by varying angle of inclination of anchors with the horizontal by varying it from $0^{0}$ to $25^{\circ}$ keeping other properties constant. The results shows that $15^{\circ}$ inclination gives highest value of FOS. Figure 7 shows the FOS for the slope with anchors reinforced at an inclination of $15^{0}$. Table 4 below shows the results for variation in angle of inclination of anchor for $S_{v}=S_{h}=2 \mathrm{~m}$ and $L / H=0.7$ for 14 number of anchors.

Table 4: Effect of angle of inclination of anchor on FOS.

\begin{tabular}{|c|c|c|c|c|c|c|}
\hline Inclination $(\boldsymbol{i})$ & $\mathbf{0}^{\mathbf{0}}$ & $\mathbf{5}^{\mathbf{0}}$ & $\mathbf{1 0}^{\mathbf{0}}$ & $\mathbf{1 5}^{\mathbf{0}}$ & $\mathbf{2 0}^{\mathbf{0}}$ & $\mathbf{2 5}^{\mathbf{0}}$ \\
\hline FOS & 1.43 & 1.49 & 1.54 & 1.59 & 1.57 & 1.55 \\
\hline $\begin{array}{c}\text { Displacement } \\
(\mathbf{m m})\end{array}$ & 59.9 & 57.2 & 56.1 & 53 & 55 & 56.4 \\
\hline
\end{tabular}




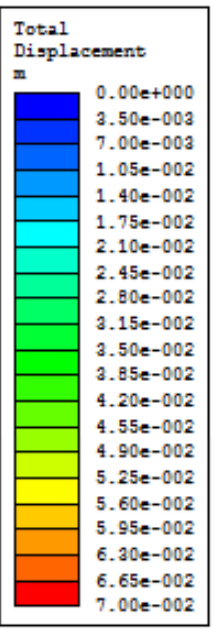

Fig. 6: FEM model of Guwahati: Displacement Contours and Factor of safety in unreinforced condition.

Critical SRE: 1.59
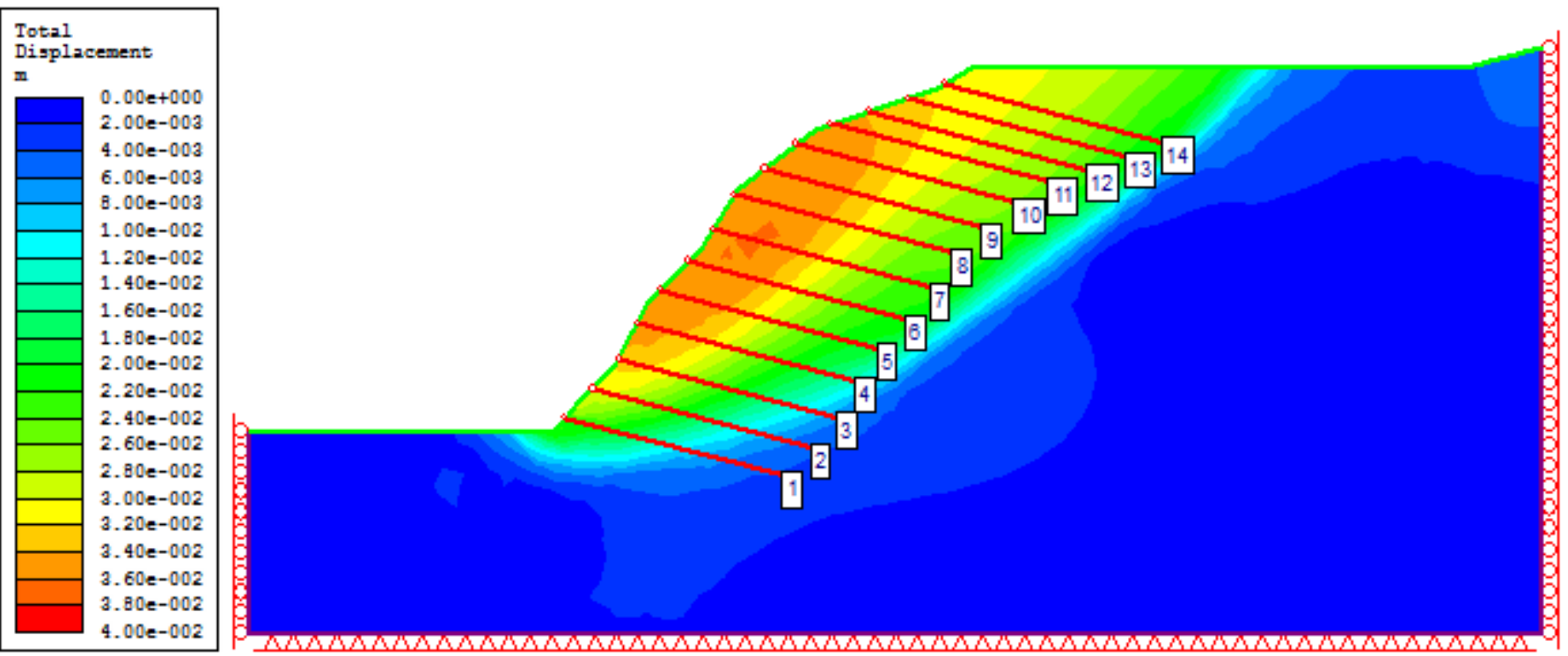

Fig. 7: FOS and Displacement contours of the slope with anchors reinforced at an inclination of $15^{\circ}$.

Length of embedment of anchors: The length of embedment was varied in ratio of height of the slopes as 0.4 times of slope height, $\mathrm{H}$ to 0.8 times of the slope height. Table 5 shows the results for variation in Length of embedment of Anchors for $S_{\mathrm{v}}$ and $S_{h}=2 \mathrm{~m}$ and $\mathrm{L}=0.6 \mathrm{H}$.

Table 5: Effect of Length of embedment of anchor on FOS.

\begin{tabular}{|c|c|c|c|c|c|}
\hline Length of Embedment (L) & $\mathbf{0 . 4 H}$ & $\mathbf{0 . 5 H}$ & $\mathbf{0 . 6 H}$ & $\mathbf{0 . 7 H}$ & $\mathbf{0 . 8 H}$ \\
\hline FOS & 1.37 & 1.48 & 1.58 & 1.64 & 1.65 \\
\hline Displacement (m) & 0.055 & 0.046 & 0.041 & 0.038 & 0.037 \\
\hline
\end{tabular}


Surcharge: As the crest of the slope may be utilised as Roadway, construction of Buildings, Reservoirs etc. therefore surcharge values from $20 \mathrm{kPa}$ to $100 \mathrm{kPa}$ were applied on the crest of the slope to get the behaviour of the slope under different surcharge loading. The results show that the anchor design with $\mathrm{S}_{\mathrm{v}}$ and $\mathrm{S}_{\mathrm{h}}=2 \mathrm{~m}$ and $\mathrm{L}=0.6 \mathrm{H}$ is capable of handling the surcharge loads over the crest. Table 6 shows the values of FOS corresponding to each surcharge increment from 0 to $100 \mathrm{kPa}$.

Table 6: Effect of Surcharge load on FOS of the slope.

\begin{tabular}{|c|c|c|c|c|c|c|c|c|c|c|c|}
\hline Surcharge (kPa) & 0 & 10 & 20 & 30 & 40 & 50 & 60 & 70 & 80 & 90 & 100 \\
\hline FOS & 1.58 & 1.55 & 1.53 & 1.5 & 1.48 & 1.46 & 1.43 & 1.41 & 1.39 & 1.37 & 1.35 \\
\hline
\end{tabular}

Spacing: Spacing between anchors were varied from $1 \mathrm{~m}$ to $2.5 \mathrm{~m}$ and the corresponding effect on FOS of the slope is noted. Horizontal and vertical spacing are kept same for an analysis. Figure 8 shows the variation with spacing at different $\mathrm{L} / \mathrm{H}$ ratios. Number of anchors for different spacings are given in table 7 below:

Table 7: Description of spacing and number of anchors used

\begin{tabular}{|c|c|c|c|c|}
\hline Spacing & $\mathrm{S}_{\mathrm{v}}=\mathrm{S}_{\mathrm{h}}=1$ & $\mathrm{~S}_{\mathrm{v}}=\mathrm{S}_{\mathrm{h}}=1.5$ & $\mathrm{~S}_{\mathrm{v}}=\mathrm{S}_{\mathrm{h}}=2$ & $\mathrm{~S}_{\mathrm{v}}=\mathrm{S}_{\mathrm{h}}=2.5$ \\
\hline Number of Anchors & 26 & 16 & 14 & 11 \\
\hline
\end{tabular}

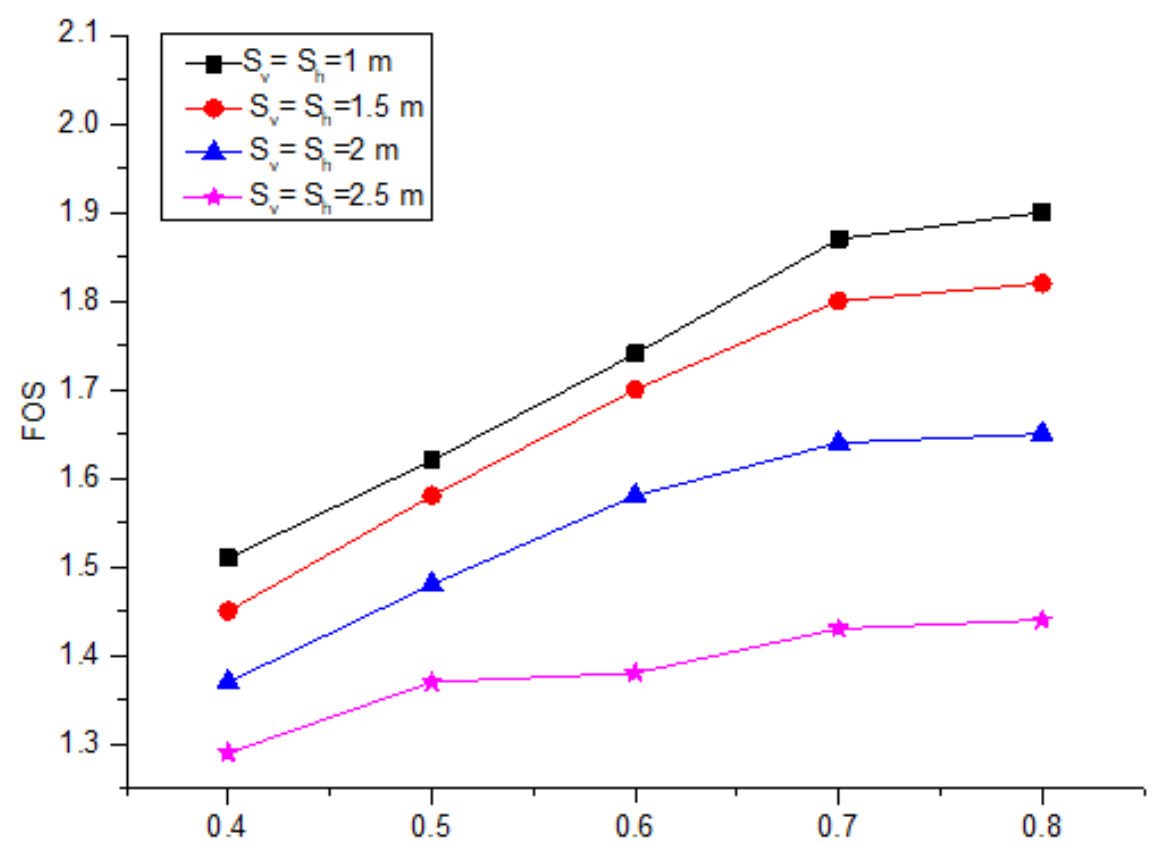

Fig. 8: Variation in FOS with Spacing at different $\mathrm{L} / \mathrm{H}$ ratios.

Pseudo static Force: To check the utility of the anchor design in the hilly regions prone to earthquake, the slope has been analysed for $a_{h}=0.1,0.15$ and 0.2. Table 8 below shows the FOS of the slope under pseudo static conditions for different seismic co-efficients

Table 8: FOS of the slope under pseudo static conditions.

\begin{tabular}{|l|l|l|l|}
\hline $\mathbf{a}_{\mathbf{h}}$ & 0.1 & 0.15 & 0.2 \\
\hline $\mathbf{a}_{\mathbf{v}}$ & 0.05 & 0.075 & 0.1 \\
\hline FOS & 1.15 & 1.03 & 0.98 \\
\hline
\end{tabular}




\section{Discussions}

i) The experimental results shows increase in load carrying capacity of the slope when the slurry is used for grouting the anchor which caused strong bonding in soil particles surrounding anchor thereby decreasing the voids around periphery of the anchor as compared to anchor without slurry.

ii) The experimental results are in good agreement with 2D FEM results from Phase $^{2}$ software with slight variations due to the effect of weight of iron plate on the crest of the slope.

iii) Both experimental and FEM results shows that optimised angle of inclination of anchors is $15^{0}$ with horizontal.

iv) It is clear from the results that not only the spacing but $\mathrm{L} / \mathrm{H}$ ratio also plays an important role in stability of anchored slopes. The combined effect of both gives better stability to the slope.

v) If the slope crest is utilised for roadway, buildings etc., it is necessary to analyse the slope for external surcharge, the anchor design is suitable for stabilising the slopes undergoing higher surcharge loads. Also the anchor design is sufficient to handle seismic loads.

\section{Conclusions}

i) The perormance of anchor in sand is enhanced by grouting it with slurry.

ii) Spacing of the anchors is an important parameter to consider while designing anchored slopes. $\mathrm{L} / \mathrm{H}=0.7$ to 0.8 should be adopted to get best results.

iii) An angle of inclination of anchor $=15^{\circ}$ with horizontal gives best results. It is recommended to adopt this angle while designing anchored slopes.

\section{References}

[1] A. G. Cushing, J. L. Withiam, A. Szwed, A. S. Nowak, "Reliability analysis of anchored and cantilevered flexible retaining structures," LSD2003: International Workshop on Limit State Design in Geotechnical Engineering Practice, 2003.

[2] R. D. Hryciw, "Anchor design for slope stabilization by surface loading," Journal of Geotechnical Engineering, vol. 117, no. 8, pp. 1260-1274, 1991.

[3] S. Mittal and S. Mukherjee, "Vertical Pullout Capacity of a Group of Helical Screw Anchors in Sand: An Empirical Approach," Indian Geotechnical Journal, vol. 44, no. 4, pp. 480-488, 2014.

[4] S. Mittal, "An Introduction to Ground Improvement Engineering," SIPL publications, New Delhi, India, 2016.

[5] P. J. Sabatini, D. G. Pass and R. C. Bachus, "Ground anchors and anchored systems," FHWA-IF-99-015, FHWA, U.S. Department of Transportation, vol. 73, 1999.

[6] D. Y. Zhu, C. F. Lee, D. H. Chan. and H. D. Jiang, "Evaluation of the stability of anchor-reinforced slopes," Canadian Geotechnical Journal, vol. 42, no. 5, pp. 1342-1349, 2005. 